\title{
Ergoterapistlerin Kişiler Arası Modları Kullanımı: Terapötik Modlar
}

\author{
Occupational Therapists' Use of Interpersonal Modes: Therapeutic Modes
}

\author{
Orkun Tahir ARAN ${ }^{1}$, Ceren DAVUTOĞLU², Ege TEMIZKAN ${ }^{3}$, Sedef ŞAHIN ${ }^{4}$, Sevginar \\ VATAN ${ }^{5}$ \\ ${ }^{1}$ Dr. Fzt., Hacettepe Üniversitesi Sağlık Bilimleri Fakültesi Ergoterapi Bölümü, Ankara \\ 2 Uz. Erg., Hacettepe Üniversitesi Sağlık Bilimleri Fakültesi Ergoterapi Bölümü, Ankara \\ 3 Erg., Hacettepe Üniversitesi Sağlık Bilimleri Fakültesi Ergoterapi Bölümü, Ankara \\ 4 Dr.Öğr. Üyesi, Hacettepe Üniversitesi Sağlık Bilimleri Fakültesi Ergoterapi Bölümü, Ankara \\ ${ }^{5}$ Doç. Dr., Hacettepe Üniversitesi, Edebiyat Fakültesi, Psikoloji Bölümü, Ankara
}

\begin{abstract}
öz
Amaç: Çalışmamız Ergoterapi lisans mezunlarının terapötik modlar olarak adlandırılan terapistin danışan ile ilişki kurma biçimlerini incelenmek amacıyla planlandı. Gereç ve Yöntem: Çalışmaya 24 kadın ve 5 erkek olmak üzere toplam 29 kişi dahil edildi. Katılımcılara Demografik Bilgi Formu ve ModÖz Değerlendirme Anketi uygulandı. Sonuçlar: Çalışmaya dâhil edilen 29 terapistin yaş ortalaması 24,24 $\pm 1,70$ yıl olarak bulundu. Ergoterapi lisans mezunlarının en sık tercih ettikleri terapötik modlar \%24,3 ile "problem çözme" ve \%24,1 ile "bilgilendirme" iken, en az tercih edilen mod ise \%9,7 ile "empati kurma" olduğu görüldü. Terapötik modlar arasından "teşvik etme" modunu tercih edenlerin daha az "empati kurma" modunu tercih ettikleri bulundu $(r=-0,44)$. Tartışma: Ülkemizde terapistlerin mod kullanımı açısından eğilimlerini inceleyen ilk çalışma olması nedeniyle öncü bulgular sağlayan çalışmamız terapistlere kendileri için uygun mod seçimi ile sağlayabileceği kazanımları hakkında olumlu yönde bilgi edinmelerine katkı sağlanabilir.
\end{abstract}

Anahtar Kelimeler: Ergoterapist; Eğitim; Profesyonel-hasta ilişkileri

\begin{abstract}
Purpose: In this study, it was aimed to examine the therapists' relationship with the client, which is called therapeutic modes of the graduates of occupational therapy. Material and Methods: This research was conducted with a total of 29 participants (24 female and 5 male). Demographic Information Form and Mod-Self Assessment Questionnaire were applied to the participants. Results: The mean age of 29 therapists included in the study was $24,24 \pm 1,70$ years. According to the results obtained; the most preferred therapeutic modalities for graduates were "problem solving" with $24.3 \%$ and "informative" with $24.1 \%$, the least preffered mode was "empathy" with $9.7 \%$. It was found that those who prefer the "Encouraging" mode preferred "Emphathizing" mode less $(r=-0,44)$. Conclusion: Our study, which is the first study that examines the tendencies of therapists in our country in terms of mod usage, may contribute to supporting therapists' positive information about the gains that therapists can achieve with appropriate mode selection.
\end{abstract}

Key Words: Occupational therapist; Education; Professional-patient relations 
Ergoterapistler, tedavi sonuçlarının belirleyicisi olarak danışanları ile tedavi süresince kurdukları etkileşimin kalitesini göz önüne alırlar (Cole ve McLean, 2003; Jenkins, Mallett, O'Neill ve ark, 1994; Rosa ve Hasselkus, 1996; Taylor, Lee ve Kielhofner, 2011). Bu etkileşim genellikle terapötik ilişki olarak adlandırıı ve iletişim, duygusal değişim, iş birliği ve terapistler ve danışanlar arasındaki ortaklık olarak tanımlanır (Cole ve McLean, 2003; Rosa ve Hasselkus, 1996). Danışan ile terapist arasındaki ilişkinin kalitesi, terapinin sonuçları için olduğu kadar, danışanın anlamlı aktiviteye dahil olduğu terapötik süreç için de önemlidir (Taylor, Lee ve Kielhofner, 2011; Pan ve Liu,2016).

Taylor (2008) terapistlerin danışanları ile olan bilinçli etkileşimlerini terapötik modlar olarak tanımlamaktadır. Terapötik modlar; savunma, işbirliği, empati kurma, teşvik etme, bilgilendirme ve problem çözmedir. Altı modun, uygulayıcıların kendini terapötik olarak kullanma becerisini geliştirmek için yürüttüğü çalışmaların temelini oluşturduğu düşünülmektedir. Taylor, kendini terapötik olarak kullanmanın şunları içerdiğini ileri sürmüştür; (1) Danışanın kişilerarası özelliklerinin tanımlanması ve (2) Kişilerarası terapi sürecine bilinçli dikkat ve danışanın intiyaçlarını en iyi karşılayan mod ya da modların seçilmesi (Taylor, 2008).

Ergoterapist ve danışan ilişkilerinde de bu altı terapötik modun yüksek bir sıklıkta ortaya çıktığı tespit edilmiştir. Terapistler doğal olarak kendi kişilikleri ile tutarlı olan modları seçip kullandıkları için, terapötik modların kullanımı terapistlerin kişilikleri kadar çeşitli ve karmaşıktır (Bonsaksen, 2013; Taylor, 2008; Taylor ve ark, 2011).

$$
\text { Çalışmamı Türkiye'de Ergoterapi }
$$

bölümünden mezun ergoterapistlerin tercih ettikleri modları incelemek amacıla planlanmıştır.

\section{GEREÇ VE YÖNTEM}

Çalışma Dizaynı

Bu çalışma, Türkiye'deki mezun ergoterapistlerin uygulamaları sırasında tercih ettikleri terapötik modlarını ortaya koymak üzere yapılmış kesitsel dizaynda bir çalışmadır. Çalışmanın veri toplama süreci Ekim 2017 - Şubat 2018 tarihleri arasında Ankara ilinde tamamlandı. Katılımcıların tamamına e-postanın Araştırma Amacıyla Kullanımına Dair Yönergeler dikkate alınarak, EAnket yöntemi kullanılarak çalışma gerçekleştirildi (Klimt ve Yang, 2004).

\section{Katılımcılar}

Çalışmaya Türkiye Yüksek Öğretim Kurumu'na bağlı üniversitelerden Ergoterapi lisans mezunu olan ve Türkiye'de aktif olarak çalışan ergoterapistler dahil edildi. Ergoterapi lisans mezunu olmayan ancak Ergoterapi bilimi alanında yüksek öğretimini tamamlamış veya devam eden rehabilitasyon uzmanları çalışma dışında bırakıldı. Araştırmacılar tarafından Türkiye'de 2018 yılı itibari ile Ergoterapi Lisans Mezunu olan 165 Ergoterapistin iletişim bilgilerine ulaşıldı. İletişim bilgilerine ulaşılan katılımcılara E-Posta yoluyla çalışmanın amacının ve kullanılacak yöntemin özetlendiği bir ön bilgi yazısı ile Mod-Öz Değerlendirme Anketi gönderildi. Gönüllülük ilkesi esas alınarak çalışmaya dahil edilen terapistlere çalışma hakkında bilgi verilerek, Helsinki Deklerasyonu'na uygun olarak aydınlatılmış onam formu alındı. E-postadaki ön bilgilendirme yazısını okuduktan sonra kendi terapötik yaklaşımlarını göz önünde bulundurarak anketi doldurmaları istendi. EPosta yolu ile ulaşılan 165 kişiden 29'u gönderilen anketi tam olarak doldurarak çalışmaya katılım gösterdi.

\section{Prosedür}

E-Posta ve E-Anket yöntemleri ile gerçekleştirilen çalışmalarda yanıt oranının yüksek tutulması amacıyla sık kontrol, hatırlatma ve takip yapılması önerilmektedir (MacKnight, 2008; Sheehan, 2001). Çalışmamızda, Mod-Öz Değerlendirme Anketi eposta yoluyla gönderildikten 2 hafta, 3 hafta ve 4 hafta sonra anketi tamamlayarak katılım gösteren kişilere teşekkür mesajı ve henüz anketi tamamlamayan kişilere hatırlatıcı bir mesaj yine E-Posta yoluyla gönderildi. 4 haftanın sonunda teşekkür ve hatırlatma mesajlarının gönderilmesi kesildi, elde edilen veriler SPSS versiyon 23.00 ile analiz edildi.

\section{Veri Toplama Araçları}

Çalışmada demografik bilgi formu ve Mod-Öz Değerlendirme Anketi kullanıldı.

Demografik bilgi formu: Demografik bilgi formu yaş, cinsiyet, eğitim süresi, mesleki deneyim süresi, çalışma kurumu v.b bilgileri elde edebilmek için araştırmacılar tarafından oluşturulmuştur.

Mod Öz Değerlendirme Anketi: Anket, terapistlerin danışanlar ile kurdukları ilişkide kendilerince doğal olan ya da rahat ettikleri ve rahatsızlık uyandıran veya doğal olmayan terapötik modların tanımlanması amacıyla kullanılmaktadır. Ölçek çoktan seçmeli 20 sorudan oluşmaktadır. Her bir soruda 4 veya 5 cevap seçeneği bulunmakta ve her seçenek terapötik modlardan birisine karşılık gelmektedir (Taylor, 2008) (Tablo 1). 

Tablo 1. Terapötik Modları Tanımlayan Maddeler

\section{Bilgilendirme}

- Danışanın geri bildirimi veya eleştirisine karşılık kendi bakış açımı savunmak.

- Danışanın uyum göstermemesi durumunda oluşabilecek muhtemel sonuçlardan bahsetmek.

- Duygusal bir danışanı aktivitelere yönlendirmek.

- Kızgın, muhalif veya başka bir şekilde uyumsuz bir danışana davranışlarının kabul edilebilir olmadığını söylemek.

- Danışana uyumsuz davranışlarını değiştirmesini tavsiye etmek.

Savunma

- Danışanların özerkliğini, haysiyetini, kişisel güç duygusunu ve yargılama kapasitelerini uzman bir rol üstlenerek küçümsememek.

- Terapistler koşullar gerektirdiği zaman danışanları adına hevesli ve güçlü eylemciler ve teşvik ediciler olarak görev almak.

\section{Teşvik Etme}

- Danışana mevcut kuvvetli yönleri ve kapasitesini hatırlatmak.

- Danışan bir başarıya ulaştığında övgüde bulunma veya pozitif, yapıcı sözler söylemek.

- Danışana durumunun iyiye gideceğini anlatmak.

- Danışana bir görevi başarabileceğine inandığımı söylemek.

\section{Empati Kurma}

- Danışanın olumsuz davranışının benim söylediğim ya da yaptığım bir şeyden mi kaynaklandığını düşünmek.

- Danışanı olumsuz duygu, düşünce ve tepkilerini ifade etmesi konusunda cesaretlendirmek.

- Danışanın bozukluğu ya da yaşam tecrübeleri hakkında kendi duygusal tepkimi ya da kişisel düşüncemi paylaşmak.

- Danışana durumunun ne kadar zor olduğunu anladığımı söylemek.

- Danışanın söylediği anlamlı bir şeyi başka sözcükler kullanarak kendisine tekrarlamak.

- Yakınlık kurmak amacıyla danışana kendim hakkında kişisel bir şey ya da yaşam tecrübesi anlatmak.

- Kendi duygusal ifadelerim ile empati kurmaya çalışmak.

- Klinik karar verme sürecinde yardımcı olması için danışan hakkındaki duygusal tepkilerime güvenmek.

- Danışanın yaşam durumu ya da problemi dolayısıyla üzüldüğümü söylemek.

- Ağlamak üzere olan bir danışana ağlamanın normal olduğunu söylemek.

- Danışanın olumsuz tepki, davranış ya da düşünce şeklinin mantıklı olduğunu söylemek.

İşbirliği

- Danışanı terapi sürecinde daha fazla karar vermesi için cesaretlendirmek.

- Danışanın problemi veya yaşam durumu hakkındaki bakış açısını desteklemek ve cesaretlendirmek.

- Herhangi bir aktivite seçmeden ya da önermeden önce danışandan geri bildirim almak.

- Danışanın terapi için kendi hedeflerini önermesini istemek.

Problem Çözme

- Danışanın mantıksız düşüncelerini düzeltmesi için sorular sormak.

- Danışanın kendi durumuna başka bir açıdan bakmasını önermek.

- Danışanın alternatif yolları tanımlaması için sorular sormak.

Kişinin 20 soruya verdiği cevaplara göre en sık hangi terapötik mod ile ilgili yanıtları seçtiği analiz edilerek kişinin genel terapötik modu çıkarılmaktadır (Taylor, 2008; Taylor ve ark, 2011).

Çalışma kapsamında Mod-Öz Değerlendirme Anketi E-Anket şeklinde düzenlenerek kişilerin bilgisayar ortamında yanıtlayabilecekleri ve yanıtları doğrudan araştırmacılara ulaştırabilecekleri şekilde tasarlanmıştır. Mod-Öz Değerlendirme Anketine ek olarak katılımcılardan çalışmakta oldukları departmanlara ve alanlara yönelik bilgilerde alınmıştır.

\section{Istatistiksel Analiz}

Veri toplanmasında kullanılan E-Anket yöntemi eksik ya da çift cevaba olanak vermediğinden 29 kişinin verilerinin de analiz için kullanılabilir olduğuna karar verilmiştir. Anket sonuçları SPSS programına girilerek özetlenmiş ve analiz edilmiştir. Katılımcıların terapötik mod seçimlerine dair frekans bilgileri Çoklu Cevap (Multiple Response) veri seti oluşturularak hesaplanmıştır (Bernstein ve Ebbesen, 1978). Katılımcıların tercih ettikleri modlar arasındaki göreceli farkın görülmesi amacıyla frekans değerleri yüzdelik 
puanlara çevrilmiştir. Terapötik modlar arasındaki ilişkinin görülmesi amacıyla bivaryant korelasyon analizi (Pearson Testi) yapılmıştır (Benesty, Chen, Huang ve ark, 2009). Çalışmamızda istatistiksel anlamlılık düzeyi $p<0.05$ olarak kabul edilmiştir.

\section{SONUÇLAR}

Çalışmaya 24 kadın 5 erkek katılım gösterdi. Katılımcıların yaş ortalamaları $24,24 \pm 1,70$, iş tecrübeleri ortalaması ise 2,62 $\pm 0,94$ yıl olarak saptandı. Katılımcıların çalışma alanları incelendiğinde ise katılımcıların 11'inin (\%38) Toplum Ruh Sağlığı Merkezlerinde, 10'unun (\%35) özel eğitim merkezlerinde, 8'inin (\%27) rehabilitasyon merkezlerinde (özel, devlet hastanesi vb) çalıştığı; 17'sının (\%58) ruh sağlığı ve erişkin rehabilitasyonu, 11'inin (\%38) pediatrik rehabilitasyon ve 1'inin (\%4) az gören rehabilitasyonu alanında çalışmakta olduğu tespit edilmiştir.

Anket sonuçlarından elde edilen verilerden oluşturulan çoklu cevap veri paketinin analizi sonucunda ortaya çıkan tanımlayıcı bilgi Tablo 2'de verilmiştir. Katılımcıların terapötik mod tercihleri ilk sırada \%24,3 ile "problem çözme" olduğu, son sırada ise \%9,7 ile "empati kurma" olduğu görülmüştür.

Katılımcıların verdikleri cevaplara göre teşvik etme ve empati kurma modları arasında anlamlı, orta düzeyde ters ilişki olduğu bulunmuştur $(p=0,016)$. Sonuçlar Tablo 3' te gösterilmiştir.

Tablo 2. Terapötik Modların Tercih Edilme Sıklığı (N=29)

\begin{tabular}{ccc}
\hline Terapötik Mod & Cevap Sayısı & Yüzdelik Karşılık (\%) \\
\hline Problem Çözme & 141 & 24,3 \\
Bilgilendirme & 140 & 24,1 \\
Savunma & 92 & 15,9 \\
Teşvik Etme & 91 & 15,7 \\
İşbirliği & 60 & 10,3 \\
Empati Kurma & 56 & 9,7 \\
\hline
\end{tabular}

Tablo 3. Terapötik Modlar Arasındaki İlişki

\begin{tabular}{|c|c|c|c|c|c|c|c|c|c|c|}
\hline \multirow[b]{2}{*}{ Problem Çözme } & \multicolumn{2}{|c|}{ Bilgilendirme } & \multicolumn{2}{|l|}{ İşbirliği } & \multicolumn{2}{|c|}{ Savunma } & \multicolumn{2}{|c|}{ Empati Kurma } & \multicolumn{2}{|c|}{ Teşvik Etme } \\
\hline & $\mathbf{p}$ & $\mathbf{r}$ & $\mathbf{p}$ & $\mathbf{r}$ & p & $\mathbf{r}$ & p & $\mathbf{r}$ & $\mathbf{p}$ & $\mathbf{r}$ \\
\hline Bilgilendirme & 0,62 &,- 174 & 0,77 &,- 182 & 0,59 &,- 200 & 0,88 &,- 062 & 0,67 &,- 095 \\
\hline İşbirliği & & & 0,74 &,- 131 & 0,69 &,- 139 & 0,24 &,- 007 & 0,39 &,- 328 \\
\hline Savunma & & & & & 0,91 &,- 324 & 0,14 &,- 170 & 0,47 &,- 072 \\
\hline Empati Kurma & & & & & & & 0,49 &,- 082 & 0,94 &,- 320 \\
\hline Teşvik Etme & & & & & & & & & $0,001^{*}$ &,$- 443^{\star}$ \\
\hline
\end{tabular}

${ }^{*} \mathbf{p}<0,05, \mathrm{r}$ : Spearman korelasyon katsayısı

\section{TARTIŞMA}

$\mathrm{Bu}$ çalışmada, Ergoterapi lisans mezunlarının terapötik modlar olarak adlandırılan terapistin danışan ile ilişki kurma biçiminin incelenmesi amaçlandı. $\mathrm{Bu}$ amaç doğrultusunda ergoterapistlerin danışanları ile tedavi süreci içerisinde iletişim kurarken kullanabilecekleri savunma, işbirliği, empati kurma, teşvik etme, bilgilendirme ve problem çözme olmak üzere 6 mod ele alındı. Çalışma sonuçlarına göre araştırmaya katılan ergoterapistlerin terapötik ilişki içerisinde kullandıkları modlarının sıralaması problem çözme, bilgilendirme, savunma, teşvik etme, işbirliği ve empati kurmadır. Dolayısıyla, katılımcıların terapötik mod tercihleri en yüksek oranda "Problem Çözme" ve "Bilgilendirme" modundan yana olurken, en az orandaki tercih ise "Empati Kurma" modundan yana olduğu görülmektedir.

Bonsaksen çalışmasında da bu çalışmanın bulgularına benzer şekilde problem çözme modu 
birinci sırada yer almaktadır. Ancak her iki çalışma son sırada yer alan mod açısından önemli bir farklılık olduğu görülmektedir (Bonsaksen, 2013). Aynı çalışmada savunma modu son sırada yer alırken bu çalışmada ise empati kurma modunun son sırada yer aldığı bulundu. Bireyci bir toplum açısından savunma modunun en son sırada yer almasının kültürel özellikler ile ilişkili olabileceğini akla getirmektedir. Taylor, çalışmasını yaptığı sıralarda "savunma" modu ile ilgili yeterli madde bulunmadığı ve yönelimsel ilişki modelinde yeni bir yapı olduğu için dahil etmediğini söylemiştir (Taylor ve ark, 2011). Ancak biz çalışmamızda savunma modunu da sorgulayarak, terapistlerin eğilimlerini incelediğimizde, tercihleri arasında üçüncü sırada yer aldığını tespit ettik. Çalışmamızda üçüncü sırada tercih edilen mod olması nedeniyle, ülkemizde terapötik yaklaşımlarda savunmacı özelliklerin etkin olabileceği öngörülmektedir.

Empati kurma modu açısından bulgular ele alındığında bu çalışma bulgularına benzer şekilde Taylor çalışmasında da söz konusu mod en son sırada yer alırken Bonsaksen çalışmasında ise dördüncü sırada yer almaktadır (Bonsaksen, 2013; Taylor ve ark, 2011). Dolayısı ile empati kurma modunun az tercih edilen bir terapötik iletişim kurma ve terapi sürecini yürütme modu olduğu söylenebilir. Terapistler açısından empati kurma modunun "Danışanın olumsuz davranışının benim söylediğim ya da yaptığım bir şeyden mi kaynaklandığını düşünmek", "Yakınlık kurmak amacıyla danışana kendim hakkında kişisel bir şey ya da yaşam tecrübesi anlatmak", "Danışanın bozukluğu ya da yaşam tecrübeleri hakkında kendi duygusal tepkimi ya da kişisel düşüncemi paylaşmak" vb. şeklinde ifadeleri içerdiği göz önüne alınacak olursa empati ve sempati arasında bir çizgide yer alabileceği, kişisel deneyimi açmayı da içerebileceği düşünüldüğünde terapi ilişkisini profesyonellikten uzaklaştırma riski taşıyabileceği şeklinde yorumlanıyor olabilir.

Taylor ve Bonsaksen (Bonsaksen, 2013; Taylor, 2008) tarafından yapılan diğer iki çalışma ile bu çalışma karşılaştırıldığında bilgilendirme modu diğer çalışmalarda alt sıralarda yer alırken bu çalışmada üst sıralarda yer almaktadır, ters bir ilişki olarak ise diğer çalışmalarda işbirliği modu üst sıralarda yer alırken bu çalışmada alt sıralarda yer aldı. Bunun toplumsal ve kültürel farklılıklardan ortaya çıktığı düşünülmektedir. Batı toplumlarının terapi sürecini danışana daha değer katarak ortak fikirler oluşturmaya yönelik şekillendirdiği görülürken bu çalışmaya katılan terapistlerin daha dikte edici özelliklerinin terapi sürecinde baskın geldiği düşünülmektedir.

Bonsaksen'in çalışmasında katılımcılar öğrencilerden oluşmaktayken, Taylor'un çalışmasına katılan terapistlerin en az 5 yıl deneyime sahip oldukları görülmektedir (Bonsaksen, 2013; Taylor ve ark, 2011). Bizim çalışmamızda ise katılımcılar 5 yıldan az deneyime sahip terapistlerden oluşmaktadır. Dolayısı ile genel olarak bazı benzerlikler bulunmakla birlikte kültür bağlamı ve deneyim süresinin karıştırıcı olabilecek etkileri de göz önüne alınarak yeni çalışmalar yapılması önerilebilir. Ayrıca boylamsal çalışmalar ile deneyim, yaş ve tecrübe ile birlikte modlar arası değişim olup olmadığı bilgilerini içeren çalışmaların yapılması, ergoterapi alanı için oldukça zenginleştirici bilgiler sağlayacağı ön görülmektedir.

Çalışmanın önemli katkıları yanı sıra bazı sınırılıkları da bulunmaktadır. Çalışmada yer alan terapötik modlar kendini bildirim ile değerlendirildi. Bu konuda danışanlara terapistinizin kullandığı terapötik ilişki hangisine uymaktadır şeklinde ikincil bir değerlendirme veya yargıcı değerlendirmesi şeklinde üçüncü göz puanlama yapılmasının olumlu katkıları olabileceği de düşünülmektedir. Ayrıca terapistlerin çalıştıkları alan ve/veya kurum bilgileri ayrıntılı olarak ele alınmamış ve değerlendirilmemiştir. Bu çalışmadaki araştırma sorularının çalışma alanı ve danışan değerlendirmesi ve birebir seans gözlemi/ yargıcı puanlaması değerlendirmelerini de kapsayacak şekilde genişletilmesi ve ilerleyen çalışmalarda bunların da ele alınması önerilmektedir.

Sonuç olarak, ülkemizde terapistlerin mod kullanımı açısından eğilimlerini inceleyen ilk çalışma özelliğini taşımaktadır. Bu doğrultuda ilerleyen çalışmalar için öncül bulgular elde edildi. Her bir modun kendi içinde güçlü özellikler taşıdığı düşünüldüğünde, terapistlerin alet çantasını güçlendirici ve zenginleştirici özelliklerinin kullanılması için kendilerine uygun modları tercih etmeleri önem arz etmektedir. Dolayısı ile ergoterapi alanındaki öğrencilik eğitimlerinde ve mezuniyet sonraki hizmet içi eğitimlerde bağlam temelli mod seçimi ile ilgili bilgilerin ele alınmasının uygun olacağı düşünülmektedir.

\section{Kaynaklar}

Benesty, J., Chen, J., Huang, Y., \& Cohen, I. (2009). Pearson correlation coefficient. In Noise reduction in speech processing (pp. 1-4). Springer, Berlin, Heidelberg. 
Bernstein, D. J., \& Ebbesen, E. B. (1978). Reınforcement and Substitution in Humans: A Multıple Response Analysıs 1. J Exp Anal Behav, 30(3), 243-253.

Bonsaksen, T. (2013). Self-reported therapeutic style in occupational therapy students. $\mathrm{Br} \mathrm{J}$ Occup Ther, 76(11), 496-502.

Cole, M. B., \& McLean, V. (2003). Therapeutic relationships re-defined. Occupational Therapy in Mental Health, 19(2), 33-56.

Jenkins, M., Mallett, J., O'Neill, C., McFadden, M., \& Baird, H. (1994). Insights into 'practice'communication: an interactional approach. Br J Occup Ther, 57(8), 297302.

Klimt, B., \& Yang, Y. (2004). The enron corpus: A new dataset for email classification research. In European Conference on Machine Learning (pp. 217-226). Springer, Berlin, Heidelberg.

MacKnight, C. B. (2008). Handbook of research on electronic surveys and measurements: Springer.

Pan, A. W., \& Liu, L. T. (2016). Therapeutic Relationship and Treatment Outcome. Am J Occup Ther, 70(4_Supplement_1), 7011510234p1$7011510234 \mathrm{p} 1$.

Rosa, S. A., \& Hasselkus, B. R. (1996). Connecting with patients: The personal experience of professional helping. The Occupational Therapy Journal of Research, 16(4), 245-260.

Sheehan, K. B. (2001). E-mail survey response rates: A review. Journal of computer-mediated communication, 6(2), JCMC621.

Taylor, R. R. (2008). Knowing ourselves as therapists: Introduction to Theuropaetic Modes. (pp 67-99). The intentional relationship: Outpatient therapy and use of self: FA Davis.

Taylor, R. R., Lee, S. W., \& Kielhofner, G. (2011). Practitioners' use of interpersonal modes within the therapeutic relationship: Results from a nationwide study. OTJR: Occupation, Participation and Health, 31(1), 6-14. 